\title{
Biological Re:Evolution The Resilient Science of Mycelium Design
}

\author{
ANGELA ROSE BRACCO \\ Californian Polytechnic State University San Luis Obispo
}

As resiliency becomes increasingly pertinent in today's conversations about human environments and natural ecologies, it becomes even more pressing that the architectural community joins forces with the natural sciences in order to have a significant impact on the manufacturing, construction, and post-deconstruction of the built environment. This conversation is imperative for the design community to have in order for them to gain a foundational mindfulness towards the concept of biological applications and how they affect the future resiliency of our planet. According to Drew Endy in Synthetic Aesthetic "The Nineteenth Century was shaped by the mechanization of the Industrial Revolution; in the twentieth century, the silicon circuitry of an Information Revolution reconstructed modern life. Now, some predict biotechnology will be the foremost driver of change for the twenty-first century." Through collaborative endeavors, biologists and architects are combining their efforts to manipulate matter in ways that could ultimately change future standards and practices in the design and building industry. Although biotechnology as a discipline encompasses many advanced endeavors, Architecture can begin addressing concerns of ecological consequences by looking at a critical piece of the puzzle: Materiality. We can distance ourselves from antiquated and harmful production practices simply by expanding the use of organic and biodegradable materials. We can no longer simply look at lifespan, but must also take into account life cycle. A particularly unique bio-composite material that is offering new opportunities in design and building materials is a mycelium inoculated substrate, and it has the potential to make a significant impact on building systems.

Currently, many significant developments are occurring in the world of mycology (the study of fungi) on a range of different architectural scales and applications. By engaging with these efforts, the architecture and design community can create the opportunity for an entirely new set of methods, assembly, and implementation. Nurturing and cultivating biological carbon-based materials can have a profound influence on manufacturing processes. Fungal Colonies, also known as mycelium, are a matrix of complex carbohydrates made up of numerous glucose molecules that appear to be a culmination of white divisions of filaments called hyphae. This network of branching fibers, when in ideal conditions, will eventually create a fruiting body more commonly known as a mushroom.

\section{ST CENTURY MATERIAL FOR 21ST CENTURY PERFORMANCE}

With building materials at the forefront of this revolution, mycelium proposes many of the benefits that biotechnology is striving to achieve. This idea is supported by Alexandra Daisy Ginsberg who said, "Through synthetic biology, living things could become both the operating system and the machine, in theory creating a technology so versatile that it could be used to produce food of a projected global population explosion and remediate the environmental damage wreaked by two centuries of industrial modernization." [1]

Currently, buildings account for over half of global energy consumption. [2] As such, it is vital that architects take the initiative to reimagine the possibilities of architecture on multiple scales: from material applications, to the overall performance of the finished product, to future implications of said product. We can no longer simply think in terms of lifespan, but we must also take into account life cycle. Life cycle refers to the vast and interconnected existence of an object or entity, far beyond its physical function and form; it challenges the idea of the one-dimensional aspect of lifespan. [3] It is for this reason that architects must rise to the occasion and partner with the natural sciences in order to make strides towards creating a more promising future. By engaging in interdisciplinary efforts, the architecture and design community can create the opportunity for an entirely new set of methods, assembly, and implementation. This is not to undermine or discredit the efforts of LEED certifications or the sustainable architecture movement, but it is imperative that we not only look at decreasing energy consumption and improving building performance, but also eliminating the trend of a carbon footprint altogether. This concept was brought to light in 2002 by ecological design activist William McDonough in his book Cradle to Cradle. According to McDonough, "efforts to reduce consumption, or make new things from waste products, or avoid problematic materials have had little impact on a global scale." [4] The ultimate message here is to shift the paradigm from placing temporary "bandage solutions" on the aftermath of the industrial revolution, to setting up an entirely new system that will build towards a more sustainable and resilient future.

It is paramount when building this sustainable future that sufficient focus is placed on the integration of biology and architecture. According to Biologist Jim Haseloff, "We often forget biology's ability to convert sunlight into chemical 


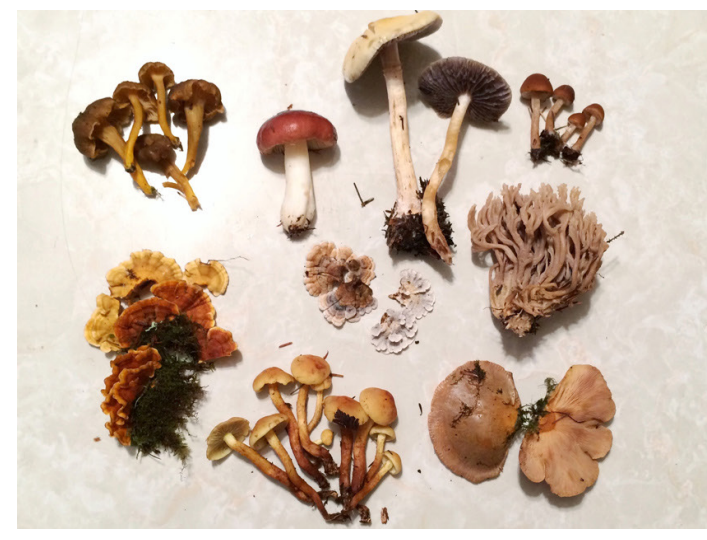

Figure 1: Mushroom varieties and mycelium of a fungus spreading through the soil. (Credit- Nigel Cattlin / Alamy).

energy, build complex structures from scratch, its adaptive, self-replicating, self-repairing capabilities, and use of its own waste material to fuel new structures, eclipsing any notion of human ingenuity."[5] With the impact of harmful building practices increasing exponentially, it has now become our duty to construct buildings that start behaving like biological systems of the earth in order to demolish our concerns with consumption, toxicity, and waste. It is a societal obligation to seek out reform and counteract the environmental repercussions of the past 200 some odd years.

This is not to say, however, that the idea of the synthetic biology revolution doesn't raise difficult questions with regards to social and ethical issues. Manipulating biology has the potential to be equally as harmful as mining precious metals or injecting pressurized gas into the earth. This relatively fledgling industry has made strides to reach mainstream recognition and procure financial support, but in our quest for lessening the impact on the environment, we must not neglect to ask ourselves the difficult questions. In our endeavors to create natural systems made from synthetic means, we must think critically about the repercussions. According to Synthetic Aesthetic, "Biology grows within the balance of ecosystems, but can commercial synthetic biology be a sustainable, renewable technology on a planet with finite resources?" [6] The planet currently seeks equilibrium, not excess, which is a paradox in regards to making a commodity of natural systems. [7] However, these new biotechnologies deserve to be investigated further if we are to find viable solutions to shift from the current industry hegemony.

\section{WHY GENERATIVE BIO-BASED MATERIALS?}

Although biotechnology as a discipline encompasses many advanced endeavors, Architecture can begin addressing concerns of ecological consequences by looking at a critical piece of the puzzle: Materiality. We can distance ourselves from antiquated and harmful production practices simply by expanding the use of organic and biodegradable materials. Interdisciplinary efforts with biotechnology can help us to create bio-composite materials deploying organic material that consumes agricultural waste, requires minimal energy to produce, and is completely biodegradable. Introducing the aspect of growing and self-generating material within the current building culture could have a profound impact on the building industry. For example, the energy that it takes to manufacture photovoltaic solar panels nearly equates the amount of energy that the panel will generate in its lifespan. [8] Reasons such as these are why scientists are trying to reengineer algae to directly convert solar energy to fuel, thus creating a more efficient system that is less toxic and is not reliant on petroleum-based products. [9] It is important to reduce the number of steps in order to render a more efficient system, by growing versus manufacturing this is achieved. Mycelium is one such material that so happens to function successfully as an architectural building material while at the same time providing a clean alternative to otherwise harmful petroleum-based products.

\section{WHAT IS MYCELIUM?}

Fungal Colonies also known as mycelium are a matrix of glycan or natural complex branched chain-like carbohydrates, made up of numerous glucose molecules that appear to be a culmination of white divisions of filaments called hyphae. This network of branching fibers, when in ideal conditions, will eventually create a fruiting body more commonly known as the mushroom. Mycelium is often found submerged in another body such as soil or other organic substrates. Typically, the common passerby will not have the opportunity to see the vast network of fibers that is submerged within the earth, but will only witness the fruiting body that lies above grade. [10]

\section{MYCELIUM IN 21ST CENTURY THINKING}

It is only through exceptional creative thought and application testing that researchers in the field have been able to develop biotech materials and figure out efficient and alternative applications for them in the building industry. In the Inventor's Studio at Rensselaer Polytechnic University, Eben Bayer and Gavin Maclntyre were challenged to come up with a socially responsible, unique, and disruptive technology. [11] It is here that Bayer conceived the idea of using grown materials such as mycelium to counter traditional manufacturing practices that 


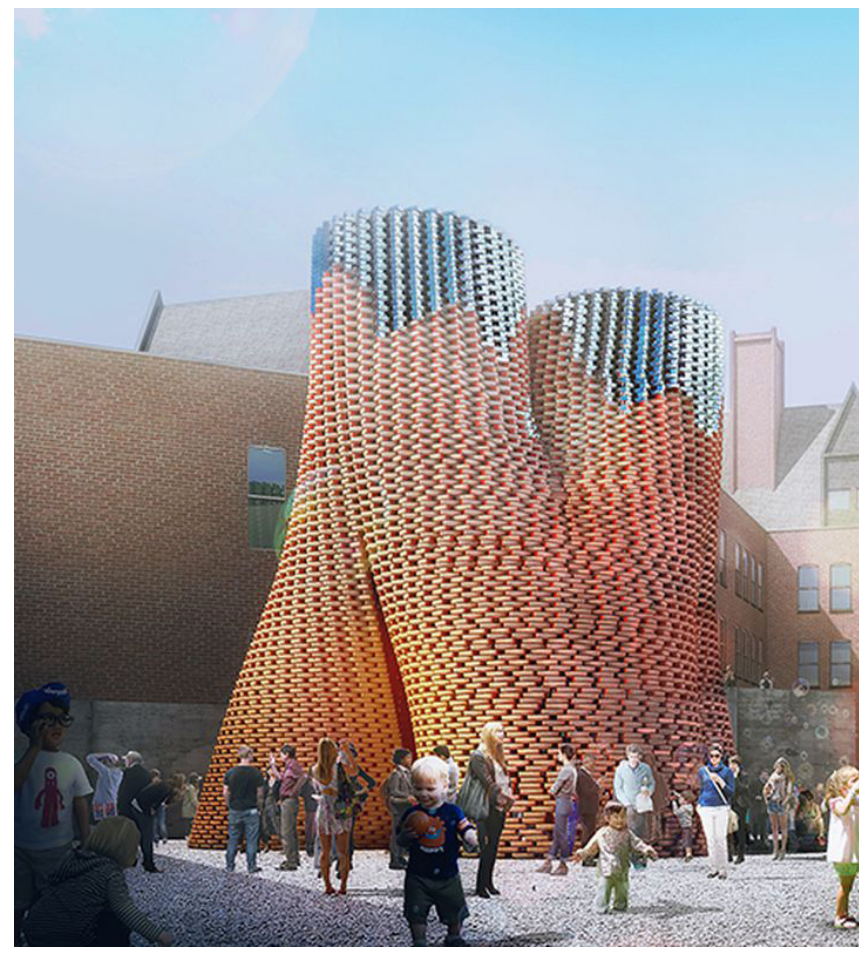

Figure 2: Hy-Fi for PS1 Moma by David Benjamin (credit David Benjamin)

create product and waste stream. Bayer thought of the idea of using mushrooms as a binding agent because of his observations on his family's maple syrup farm. It was there where he observed the hyphae of the mycelium stitching together wood chip piles before they were used to fuel the annual fires. Bayer and Maclntyre thought it would be interesting if one could grow a material that could replace plastic and Styrofoam in various applications such as packaging and building materials. Shortly after this discovery and further development, Bayer and Maclntyre formed what is known today as Ecovative.

"Ecovative procures someone else's low-value waste stream, and 100 percent of that waste stream will make it into a final product. Ecovative is seeking to create not just a comparable product for packaging, and insulation but a product that is environmentally responsible, cheaper, and performs at a higher level than existing products on the market. [12] Substrate Material Consists of the following: cottonseed hulls, rice hulls, corn stover, or hemp hulls. The first step in the process is to use a process that pasteurized the substrate with pressurized steam. Ecovative's mission statement, "is to envision, develop, produce, and market Earth-friendly materials, which, unlike conventional synthetics, can have a positive impact on our planet's ecosystem." [13]

Little did Maclntyre and Bayer know that not only could mycelium be used as a binding agent, but also that the cellular structure of the mycelium so happens to have many desirable qualities for architectural applications. In short, the end product is a strong and lightweight material. The strength of the material is attributed to the high percentage of chitin that is found in the composition of the cellular walls of the mycelium. Most people are familiar with chitin in regards to its presence as the primary structure in crustaceans and insects. The chitin also happens to make the material hydrophobic and fire retardant. This bio-composite material takes considerably less energy to produce, is easily formed into custom geometries, provides sound mitigation, is fire resistant, and is completely biodegradable. [14]

\section{MYCELIUM IN 21ST CENTURY DESIGN}

Currently, many significant developments are occurring in the world of mycology (the study of fungi) on a range of different architectural scales and applications. According to John Maeda, President at The Rhode Island School of Design, "Just as post-war designers Ray and Charles Eames showed us how molded plywood techniques for building airplane wings could result in unexpected, and now timeless, pieces of furniture, artists and designers like Alexandra Daisy Ginsberg are showing us how bacteria and other biological building blocks may give us entrée to an entirely new species of experiments."[15] Artist, Phillip Ross has been manipulating mycelium on an architectural scale for the past several years. He founded Mycoworks in an effort to revolutionize the materials industry by experimenting with carbon-neutral, chemical free and biodegradable material in real life functional structures. [16] Another example is The Fungi Mutarium, a collaborative project between Designer Katharina Unger, scientists at Utrecht University, and Julia Kaisinger of LIVIN design studio. Together they started experimenting with a rare fungus found in the Amazonian rainforests of Ecuador called Pestalotiopsis microspore. They discovered that this specific fungus species is capable of digesting polyurethane plastics. The project prototype combined mycelium and agar in sphere shaped vessels that held the plastic while the microbial encasement devoured it over the course of several months. [17] On a larger and more architectural scale, David Benjamin created a $\mathrm{Hy}-\mathrm{Fi}$, an organic tower created from mushroom modules. This was installed as a temporary installation for PS1's summer Warm Up music festival. The structural shape of the form created cooling air movement and provided a shady place of respite from the New York summer sun. [18] These examples give rise to the many possible applications of mycology for next level discoveries in design and building. It is imperative that the design industry keeps engaging with these materials in new and stimulating ways.

\section{BIOLOGICAL BOOLEANS}

In pursuit of this agenda, the author ran a project, titled Biological Booleans: homegrown geometric solids in a Fall term design studio. This project served as a bridge project that mediated students' transition from the first year to the second-year curriculum at California Polytechnic State University San Luis Obispo, an institute with a strong affinity towards hands-on fabrication. In the first-year curriculum, 


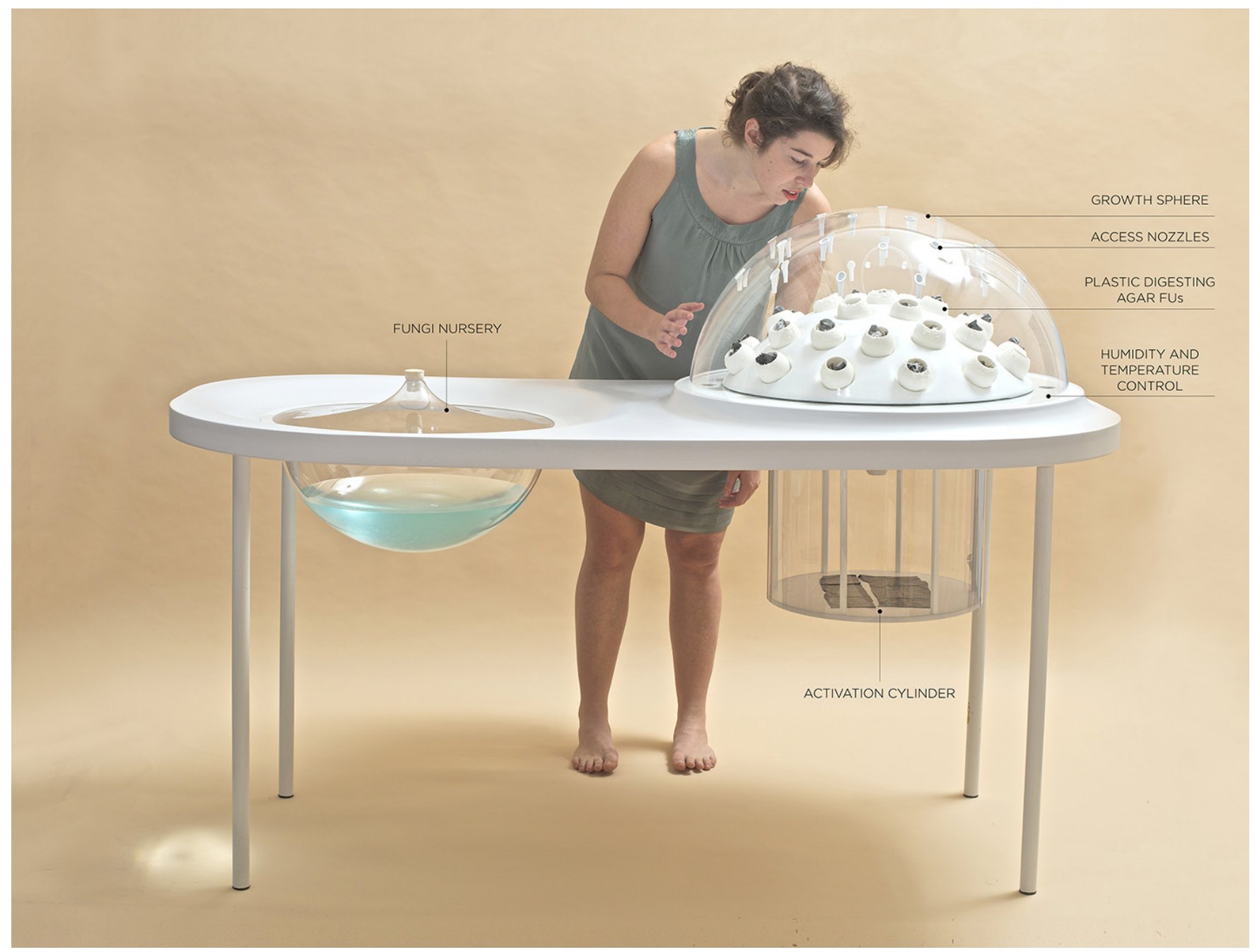

Figure 3: The Fungi Mutarium (credit Livin)

the students are required to make two full-scale projects; one is an installation that attaches to an existing building, and the other must be transported over 1.5 miles and hold the weight of several students overnight. These projects are also heavily reliant on group work and are focused on developing skills, craft, and composition. In the fall quarter of the Second year, before venturing into their small-scale architectural project, the students, were given a warm-up exercise that assisted in the transition from the first year, introduced a prescriptive design process, and an overview of working with mycelium.

In order to devise a strategy to deploy the experimentation of the bio-composite materials in Biological Booleans, I first had to establish a framework and implementation strategy. I felt that it was important to first assign the design portion of the project in order to ensure quality and authenticity of the design process, as well as not to overwhelm the students with the exciting and daunting task of working with a biomaterial. It was pertinent to the design process that the students be given very specific design drivers that assisted them in formulating a deliberate methodology grounded in a systematic examination. I began with the following three operations:

1. Each student was given a verb cataloged by Stan Allen in Landform Buildings. This verb was intended to add richness along with an element of research to the following iterative steps.

2. Each student was required to go through the following Boolean operations in Rhino.

For each of the following, use a variety of Boolean operations and produce a series of 3 volumes:

- Use only two volumes of one shape (i.e. only boxes)

- Use only three volumes of one shape

- Use only five volumes of one shape

- Use only two volumes of two shapes (i.e. only boxes and spheres)

- Use only three volumes of two shapes

- Use only five volumes of two shapes 


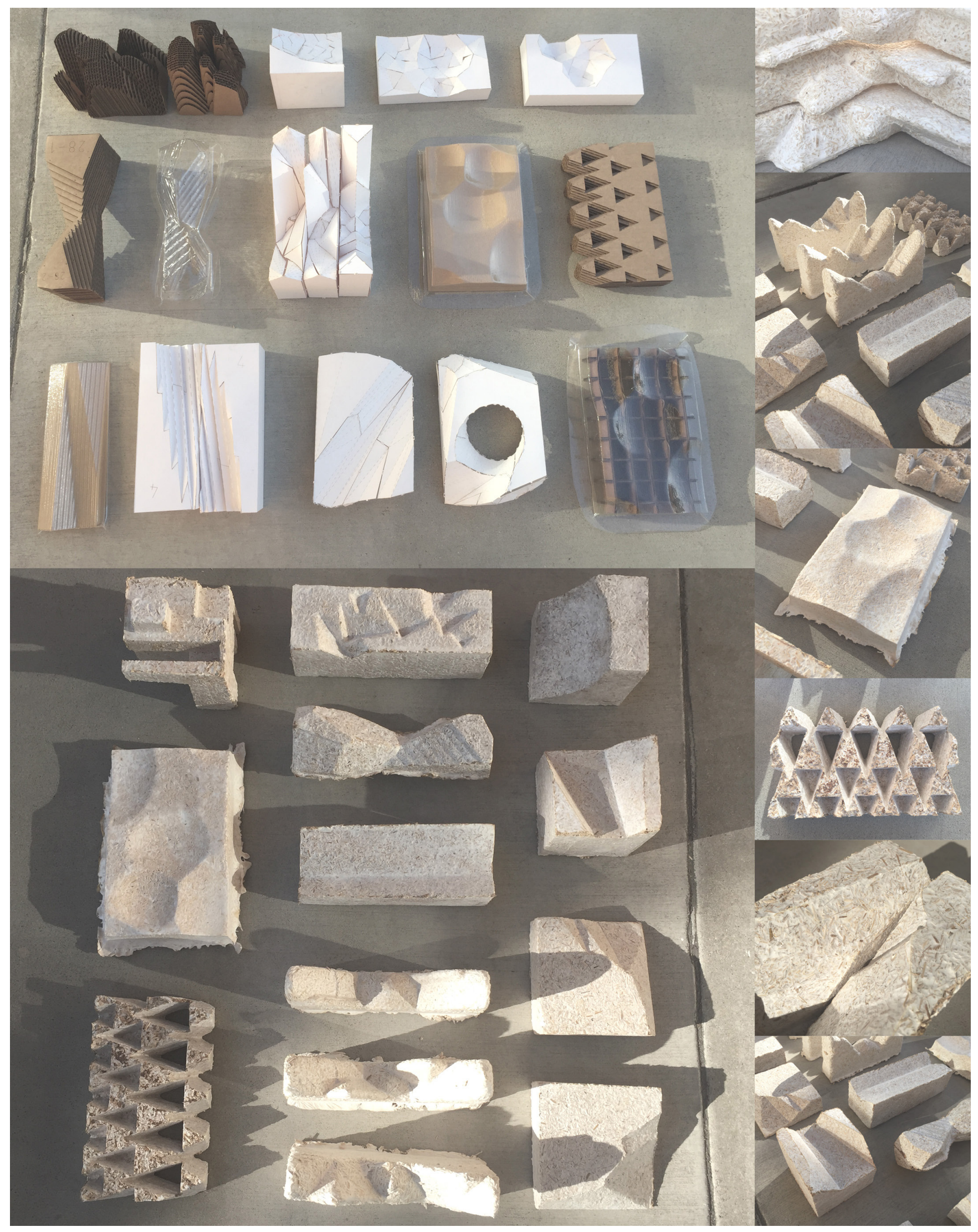

Figure 4: Final Mycelium Modules 
- Use an unlimited number of volumes of one shape (i.e. only boxes)

- Use an unlimited number of volumes of two shapes (i.e. only boxes and spheres)

- Use an unlimited number of volumes of three shapes (i.e. only boxes, spheres, and cones)

- Use your own methodology (wildcard)

3. Each student was given one of three rectilinear template geometries to limit their experimentation. These were meant to give constraints and variability amongst the cohort.

Part A rendered 30 objects, Part B rendered 9 objects and part $\mathrm{C}$ rendered 3 . At this phase of the project, the students were asked to upload their three 3D models from Rhino into Autodesk's program, Slicer, [19] and then laser cut 3 physical models. After going through several more phases of refinement, a final module or family of modules were selected to be made out of mycelium. The students then made form work, from a myriad of processes to create at least five molds. These molds were eventually filled with the mycelium inoculated substrate and left for 5 days to grow.

The mycologist, Sue Van Hook at Ecovative, has been selectively refining different combinations of substrate material and mushroom species in order to isolate certain characteristics. Currently, my students are working with a Ganoderma species of mycelium that has been inoculated in a substrate consisting of $50 \%$ corn stover and $50 \%$ hemp hulls. Ganoderma mushrooms are white rot, wood-decaying fungi found on dead or dying hardwoods and occasionally conifers. [20] Ecovative selected this specific combination of materials because it is a stable and sturdy mycelium species that has been found to perform well in an educational setting. This 50/50 mixture has enough precision to pick up resolution and detail from the mold that it resides within while also producing a result of the intended formwork with minimal degradation.

\section{FURTHERING MYCELIUM IN 21ST CENTURY ARCHITECTURE}

Five days passed and the mycelium had been removed from the constructs of its' framework. The design outcomes were greatly varied, reflecting each student's individual approach to design and formwork construction. Overall, the students demonstrated a high level of execution and concept design in the beginning stages of the project but struggled most with the production aspects such as CAD/CAM applications and general fabrication. For the most part, we found that overall craft and precision, regardless of mold type, was the biggest factor in contributing to the best outcomes. Due to the short duration of the project, many students struggled with the outcomes of the CNC mill and defaulted to using laminated cardboard and metal tape construction. I was pleasantly surprised at the crispness of the edges and surface texture that came from the cruder formwork. Considering it was the first time that students worked with bio-composite materials, we generated relatively successful mycelium modules.

The biggest takeaway from the project was the exposure to biological materials and the students' excitement toward future applications. During the exhibition, the atmosphere was buzzing with excitement and curiosity about what the material is and how it works. As an educator, it was rewarding to see the students educating their peers about what they learned. I found this project to be an indicator that students are open and receptive to learning about biotechnological solutions. It is imperative to educate current architecture students early on so that they feel comfortable with not only the idea of using biomaterials but also understanding that we can and must make strides to change our standards of building practices.

\section{ENDNOTES}

1 Alexandra Daisy Ginsberg, Jane Calvert, Pablo Schyfter, Alistair Elfick, Drew Endy, Synthetic Aesthetics Investigating Synthetic Biology's Designs on Nature (United States of America: MIT Press, 2014), 100-135.

2 International Energy Outlook 2016, accessed September 29th 2017, https:// www.eia.gov/outlooks/ieo/pdf/0484(2016).pdf table F1

3 Alexandra Daisy Ginsberg, Jane Calvert, Pablo Schyfter, Alistair Elfick, Drew Endy, Synthetic Aesthetics Investigating Synthetic Biology's Designs on Nature (United States of America: MIT Press, 2014), 100-135.

4 William McDonough and Michael Braungart, Cradle to Cradle: Remaking the Way We Make Things (New York: North Point Press, 2002).

5 Alexandra Daisy Ginsberg, Jane Calvert, Pablo Schyfter, Alistair Elfick, Drew Endy, Synthetic Aesthetics Investigating Synthetic Biology's Designs on Nature (United States of America: MIT Press, 2014), 100-135.

6 Ibid, 100-135

7 Ibid, 100-135

8 Ibid, 100-135

9 Ibid, 100-135

10 Paul Stamets, Mycelium Running How Mushrooms Can Help Save the World (Berkeley: Ten Speed Press, 2005), 10-16.

11 Penelope Zeller and Dena Zocher, "Ecovative's Breakthrough Biomaterials," Fungi Volume 5:1 Spring 2012, Page 53, http://www.fungimag.com/spring2012-articles/LR_Ecovative.pdf).

12 Ibid, 53

13 Ibid, 53

14 "Mission Statement," Ecovative Ilc., accessed September 29th, https://www. ecovativedesign.com/about

15 Alexandra Daisy Ginsberg, Jane Calvert, Pablo Schyfter, Alistair Elfick, Drew Endy, Synthetic Aesthetics Investigating Synthetic Biology's Designs on Nature (United States of America: MIT Press, 2014).

16 On Mycotecture: Breakfast with Phil Ross, accessed September 29th 2017 , https://www.fathomers.org/blog/on-mycotecture

17 Chow Down on a Plastic-Eating Fungus Plastic trash could have a delicious future, accessed September 29th 2017, www.smithsonianmag.com/ smart-news/chow-down-plastic-eating-fungus-180958127/

$18 \mathrm{Hy}-\mathrm{Fi}$, The Organic Mushroom-Brick Tower Opens At MoMA's PS1 Courtyard, accessed September 29th 2017, https://www.archdaily.com/521266/ hy-fi-the-organic-mushroom-brick-tower-opens-at-moma-s-ps1-courtyard

19 Slicer Autodesk ${ }^{\otimes}$ is a program to turn your digital 3D models into 2D patterns that you can cut out of any flat material. Apply various slicing techniques to your model and create $2 \mathrm{~d}$ plans in EPS, DXF or PDF formats that you can cut using a Laser cutter or CNC machine.

20 Midwest American Mycological Information http://www.midwestmycology.org Mushrooms/Species\%20listed/Ganoderma\%20species.html 